\title{
MANUEL PUIG \\ (1932-1990)
}

POR

PAMELA BACARISSE

University of Pittsburgh

Con la trágica y temprana muerte, a los cincuenta y siete años, del novelista, guionista y dramaturgo argentino Manuel Puig se ha empobrecido la vida de todos los que le conocíamos. No podemos menos de reaccionar de la manera más infantil (como si tuviéramos cinco años y no supiéramos nada sobre la vida), preguntándonos inútilmente cómo puede morirse una persona tan joven, tan gentil y con tanto talento. Mas por espontáneos y sinceros que sean estos clisés inmaduros e insensatos, no alcanzan a expresar nuestro asombro y dolor... e incluso nuestra ira ante tal injusticia: para conseguir eso nos haría falta algún metalenguaje todavía por inventar.

La simpatía de Manuel Puig se evidenciaba inmediatamente en el calor de su mirada, su sonrisa encantadora y su abierta disposición. Apreciaba mucho a los amigos; nunca se olvidaba de escribirles, por ocupado o preocupado que estuviese. Hasta usaba una agenda especial para apuntar la fecha de la llegada de las cartas para no dejar pasar demasiado tiempo antes de responder. Y si uno de nosotros faltaba, pronto llegaba una carta quejumbrosa pidiendo la razón por el largo silencio. Siempre estaba dispuesto a ayudar a los que estudiaban su obra, a asistir a congresos, a dar entrevistas, a prestar materiales críticos difíciles de encontrar y a conocer personalmente a sus admiradores. Sin embargo, lo que más impresionaba en él era su timidez, hipersensibilidad y una ausencia total de vanidad; no se sentía cómodo en reuniones presuntuosas de literati (recuerdo que un autor brasileño conocido me dijo una vez: «Sólo le gusta estar con la gente que le gusta»), y la inminente aparición de cada nuevo libro o estreno teatral le llenaba de terror. Luego, si las reseñas eran buenas, le costaba creerlo; las negativas le herían profundamente. Pero su modestia y reserva 
ocultaban un sentido de humor irónico, travieso y no poco campy que le granjeó las simpatías de sus amigos. Fue un compañero divertido.

Tuvo una vida bastante peripatética, siempre en busca del lugar ideal. Nació el 28 de diciembre de 1932 en General Villegas, el pueblo cultural y físicamente estéril de la pampa argentina, que más tarde había de utilizar como escenario de sus dos primeras novelas, la casi autobiográfica $L a$ traición de Rita Hayworth (originalmente titulada Pájaros en la cabeza, terminada en 1965, pero no publicada hasta 1968) y Boquitas pintadas (1969). A la mayoría de los personajes de estas obras tempranas, Buenos Aires les parece la meca del mundo; la desilusión de los que por fin se encuentran allí (como Nené en Boquitas pintadas) casi seguramente refleja la reacción del autor mismo cuando de niño abandonó su pueblo natal para ingresar en un colegio bonaerense. No obstante, este período contribuyó tanto a su visión del mundo como lo habían hecho anteriormente las frecuentes visitas al cine, con su madre, en Villegas; fue entonces, en Buenos Aires, por medio de la película de Hitchcock Spellbound (Cuéntame tu vida, en español; 1945), cuando descubrió las teorías de Freud. También en esa época empezó a leer vorazmente (cuando, más tarde, decía que nunca había leído nada quería crear una imagen de sí mismo distintiva e interesante, aunque no era verdad), y decidió hacerse director de cine, inspirado en un principio por una película de Henri-Georges Clouzot, Quai des Orfèvres (1947). Sin embargo, aunque no perdió sus ambiciones cinematógraficas, su interés por las lenguas extranjeras (hablaba bien el inglés, francés, portugués e italiano) y, aún más importante, su convicción inquebrantable de que «la vida» se encontraba en otra parte, ingresó primero en la Facultad de Arquitectura y luego en la de Filosofía.

En 1953, cuando tenía veinte años, hizo su servicio militar, pasando lo que solía llamar «un año horroroso» de traductor en las Fuerzas Aéreas Argentinas. Al terminar esta pesadilla, empezó su vuelta al mundo. Estuvo en Italia, París, Londres y Estocolmo, dando clases de español y lavando platos en restaurantes, cada día más seguro de que él era un fracaso total. Pero por lo menos tuvo tiempo para escribir dos guiones cinematográfi$\cos .$. en inglés, claro, porque para él ésta era la lengua del cine. No consiguió vender ninguno de los dos. El primero era una mezcla de Cumbres borrascosas y Tea and Sympathy, según decía él, escrito para la actriz Vivien Leigh; en el segundo, Summer Indoors, imitaba el diálogo típico de las comedias de Cary Grant e Irene Dunne.

En 1960 regresó a Argentina, donde escribió La tajada, su primera obra en español. Tampoco tuvo éxito. Se alegó que el autor no estaba bastante enterado sobre el tema (el peronismo), pero el diálogo fue alabado. Hoy lo fascinante de este guión es la presencia de tantos elementos que 
habían de encontrarse en su obra madura: los nombres (Nélida, Esther, Mariester, «la Rita Jáivor»), una familia «de apellido» como la de Valentín en El beso de la mujer araña, referencias a boleros (para mujeres u hombres afeminados), tangos (para hombres machos) y otros productos culturales específicos, un «hombre superior», semejante a Pozzi en Pubis angelical, que no quiere que se emancipe su amada, la cursilería, un padre pobre pero agresivo (como Berto en La traición de Rita Hayworth) y, claro, indicaciones de cómo fue la vida bajo Perón.

Parecía que todos sus problemas se iban a ressolver cuando, en 1961, ganó una beca para ir a Roma a trabajar en la famosa Cinecittà; pero en seguida descubrió que el mundo de la producción de películas no se parece nada al mundo representado por ellas, en particular por las de Hollywood, y su enorme desilusión está reflejada en su quinta novela, Pubis angelical. A los treinta años se encontraba en Roma sin trabajo y sin sentido de dirección. El mismo ha contado en varias entrevistas que fue precisamente entonces, en ese momento de crisis, cuando empezó un nuevo guión que pronto se convirtió en la novela La traición de Rita Hayworth. Solía decir que la forma insólita de la primera sección del libro, con su diálogo casi impenetrable, se basaba en la presencia de voces que recordaba: las de una tía suya, de su madre y de otros parientes. Pero el único borrador que he visto (y creo haberlos visto a todos) es muy distinto de la versión final; lo más llamativo es que no hay diálogo. Evidentemente trató de escribir una novela tradicional para casi inmediatamente darse cuenta de lo que no dejó de mantener durante la vida entera: que no se sentía cómodo con la narración en tercera persona.

Inmigró a los Estados Unidos en 1963. Su horario de empleado de Air France le dio horas libres para terminar la novela. La iba a publicar la editorial barcelonesa Seix Barral, pero cuando surgieron problemas de censura se preparó otro contrato, esta vez en Buenos Aires. Allí también sufrió un revés el proceso de publicación, y por la misma razón. Aunque parecía que nunca saldría su primer libro, Puig se puso a escribir el segundo, Boquitas pintadas. Cuando por fin se publicó La traición, en 1968, no fue bien recibido; el tono de gran parte de las reseñas era incomprensivo. Entre tanto, gracias a la intervención de Juan Goytisolo, la editorial parisiense Gallimard publicó la traducción francesa de Boquitas pintadas, libro que pronto fue clasificado por Le Monde como uno de los mejores publicados en 1968-1969. Por eso no tardó en salir la versión española, teniendo tanto éxito que los críticos y el público se sintieron obligados a revalorar el libro anterior. Sólo entonces entró éste en la lista de best-sellers.

A causa de la hostilidad de las autoridades peronistas («muchas cosas desagradables ocurrieron», solía decir), de su incomodidad ante lo que 
designaba «el gigantesco ego argentino» y quizá sus sueños de la vida ideal, su peregrinación continuó. Vivió en México, pasó dos años más en Nueva York y cuando por fin se mudó a Río de Janeiro parecía haber encontrado lo que buscaba: «o verdadeiro paraíso terrestre, sonho de beleza e humanismo», en sus propias palabras. Se adaptó bien al Brasil e incluso escribió la primera versión de su penúltima novela, Sangre de amor correspondido (1982), en portugués. Parecía tan a gusto en su duplex fresquito de Leblon, escasamente amueblado pero lleno de plantas tropicales; su madre, con quien cenaba casi todas las noches, estaba cómodamente instalada en un apartamento muy cerca del suyo. Los periódicos brasileños empezaron a designarle «o carioca Puig» y todos pensábamos que allí se quedaría.

Pero una vez más acabó por desilusionarse. La situación económica brasileña, la violencia, la contaminación en la playa de Leblon - donde nadaba todos los días-, varios disgustos profesionales e indudablemente su perenne deseo de encontrar un lugar perfecto le movieron a abandonar Río de Janeiro en 1989 para instalarse en México. Fue allí, en Cuernavaca, donde murió el 22 de julio de 1990.

Tuvo la capacidad de superar los muchos contratiempos con los que se enfrentó durante su vida sin amargarse. Con la excepción de La traición de Rita Hayworth, Boquitas pintadas y —está de más decir-- su cuarta novela, El beso de la mujer araña (1976), sus obras no fueron muy bien acogidas. The Buenos Aires Affair (1973) fue proscrita en Argentina, y en España también la censura franquista prohibió su publicación (salió allí, por fin, en 1977, dos años después de la muerte de Franco; y entonces, según mantenía él, nadie lo entendía). Pubis angelical (1979), Maldición eterna a quien lea estas páginas (1980), Sangre de amor correspondido y Cae la noche tropical han sido más bien desatendidos, aunque Sangre tuvo éxito en Francia y ganó un premio importante en Italia, y a pesar de su fama, nadie se interesó por su obra temprana: cuentos, guiones y otras piezas más bien cortas, como «El detective negro» (publicado en la revista española Bazaar, que ya no existe), Gratas veladas de sociedad (escrito para Dolores del Río) y Muy señor mío (una comedia musical). Además, sus guiones comerciales (la versión fílmica de El lugar sin límites, de José Donoso, por ejemplo) no han sido reconocidos y algunos de ellos fueron cambiados sin su permiso (La cara del villano) o no llegaron a rodarse (Recuerdo de Tijuana). Aunque la versión cinematográfica de Boquitas pintadas tuvo muchísimo éxito en Argentina, nunca recibió sus derechos de autor a causa de la oposición de Isabelita Perón. Y El beso de la mujer araña no salió allí hasta muchos años después de su aparición en otros países, y aun entonces nadie lo reseñó. Se dedicó casi exclusivamente al 
teatro durante los años ochenta, pero no tuvo el éxito que hubiera querido tener con Bajo un manto de estrellas o Gardel. Las excepciones eran Ia versión teatral de El beso de la mujer araña y, más tarde, El misterio del ramo de rosas. Esta fue calurosamente acogida en Londres cuando la representaron en el Bush Theatre (algo como los teatros «off-Broadway») con la intención de trasladarla al West End; pero el teatro fue destruido por un incendio en plena temporada, imposibilitando así el traslado. En los últimos meses de su vida se presentó una versión musical de El beso de la mujer araña «off-Broadway», dirigida por Hal Prince, pero otra vez hubo problemas: los críticos de The New York Times la reseñaron antes de la fecha combinada y, para citar a Puig mismo, «la masacraron». Seguramente de haber vivido también hubiera superado este contratiempo. La última carta que recibí de él termina: «Sigo vivo. No sé cómo...»

Indudablemente, la posteridad le va a compensar la indiferencia e ignorancia de algunos críticos. Se verá (ya se empieza a ver) la importancia de Manuel Puig no sólo en el campo literario latinoamericano, sino para la literatura en general. Fue un innovador sin par tanto desde el punto de vista formal como en su temática. Un día quizá se llegará a un consenso sobre la definición del término «post-boom»; pero aun si esto nunca ocurre, todos tendremos que admitir que, sea lo que sea, lo inició Puig, escribiendo ya en los años sesenta, en pleno «boom», novelas totalmente nuevas. Sus formatos, cada uno distinto del anterior, eran atrevidos y, por esta razón, arriesgados. Utilizaba el cine, el folletín, la novela policíaca, la cultura de masas, diarios, recortes periodísticos, diálogos unilaterales, partes policiales, respuestas a preguntas inexistentes y muchos más elementos inesperados años e incluso décadas antes de que lo hicieran algunos que actualmente se consideran pioneros tanto en Europa como en las Américas. Escribió dos novelas (Maldición eterna y Cae la noche tropical) en diálogo, otra (Sangre de amor correspondido) que es puro monólogo. Yuxtaponía fragmentos de guiones fílmicos con el texto. Incluía narraciones enteras en éstos que aparentemente y a primera vista poco tenían que ver con ellos. Fue el maestro de la mise en abîme. A diferencia de algunos autores del «boom», escribía de una manera sencilla, utilizaba un lenguaje mimético (por lo cual se le censuró no pocas veces) y siempre apropiado para su tema o su personaje.

Pero lo más significativo era su temática iconoclasta. Por primera vez teníamos un autor que cuestionaba abiertamente lo que los demás parecían aceptar: el machismo, el estoicismo, el papel sumiso de la mujer y de los inadaptados...; en fin, las reglas sociales que algunos, por mucho que se esforzaran, no eran capaces de seguir. Al mismo tiempo, aceptaba lo que siempre se había rechazado: la humanidad del marginado, el poder de la 
ilusión, la relación entre la explotación sexual y la política, el consuelo de los sueños románticos irrealizables, la maravilla que debiera ser, y quizá pudiera ser, el amor. Claro, muchos de estos conceptos son mutuamente incompatibles:- de ahí su omnipresente ambivalencia, su desgana antè la mera posibilidad de indicar soluciones. En entrevistas profería teorías sobre los modos de mejorar la sociedad, las cuales siempre implicaban un cambio en nuestra actitud para con los papeles inflexibles del hombre y la mujer. Aconsejaba una visión más sensata del mundo, más realista e igualitaria, menos supersticiosa y mucho menos acondicionada por una moralidad inventada. Pero al mismo tiempo él fue un romántico perdido: creía en el amor más allá de la muerte, adoraba los melodramas que algunos críticos suponen que él condenaba en sus libros y le emocionaban «las grandes aventuras de la imaginación» (sus propias palabras). Fue un alma dividida.

A final de cuentas, la confusión ideológica y la ternura de todas sus obras reflejaban su propia ambivalencia ante la vida y su compasión por los desvalidos que somos todos. Lo que le interesaba más que nada era la condición humana y las maniobras complejas, variadas y a menudo contraproducentes del individuo en busca de la dicha. Hablando de El misterio del ramo de rosas, hace unos años dijo: "Mis personajes se encuentran aprisionados por conflictos dolorosos, no tienen alternativa. El dolor es tan fuerte, que tienen que buscar una solución dentro de sí mismos. No se trata del escapismo.» Esto se podría decir de todo lo que escribió. 